\title{
SUPPLY CHAIN COST MANAGEMENT AND VALUE-BASED PRICING
}

\author{
Martin Christopher \& John Gattorna
}

\author{
Martin Christopher* \\ School of Management \\ Cranfield University \\ Cranfield University Bedford \\ England MK43 OAL \\ e-mail : m.g.christopher@cranfield.ac.uk
}

John Gattorna

c/o Sydney Business School, L14

175 Liverpool Street

Sydney, NSW 2000

Australia

e-mail : john@gattorna-alignment.com.au

*corresponding author 


\section{Biographies}

\section{Martin Christopher}

Martin Christopher is Professor of Marketing and Logistics at Cranfield School of Management where he chairs the Centre for Logistics and Supply Chain Management, the largest activity of its type in Europe. The work of the centre covers all aspects of transportation and logistics and offers both fulltime and part-time Masters degree courses as well as extensive management development programmes.

\section{John Gattorna}

Dr John Gattorna is Professorial Fellow in Supply Chain Management, and Director, Supply Chain Research Centre, Sydney Business School. He is also Visiting Professor in Logistics and Supply Chain Management at Cranfield School of Management. 


\section{SUPPLY CHAIN COST MANAGEMENT AND VALUE-BASED PRICING}

Continued deflationary trends in many markets around the world are creating greater pressure for cost reduction in order that margins can be maintained. Customers and consumers are increasingly value driven and consequently less brand or supplier loyal. In this more challenging world there is a growing recognition that the supply chain provides one of the last remaining opportunities for significant cost reduction.

This paper presents evidence to support this viewpoint and suggests an approach to supply chain alignment that can enable cost reduction opportunities to be identified and, through collaborative working, to be actioned.

The opening years of the new Millennium have seen the emergence of new deflationary pressures. Whilst trends to price reduction may not be universal there can be no doubting that most markets are more price competitive today than they were a decade ago. Prices in the high streets and the shopping malls continue to fall in many western countries and upstream of the retail store the prices of components, raw materials and industrial products follow the same downward pattern.

Whilst some of this price deflation can be explained as the result of normal cost reduction through learning and experience effects (1), the rapid fall in the price of many consumer goods has other causes. Figure 1 shows the comparative rate at which VCR and DVD player prices fell in the UK market. The striking feature is that whilst it took 20 years for a VCR to fall in price from $£ 400$ to just over $£ 40$, it only took 4 years for a DVD player to fall by the same amount. The same phenomenon is apparent in markets as diverse as clothing, home furnishings and air travel. 


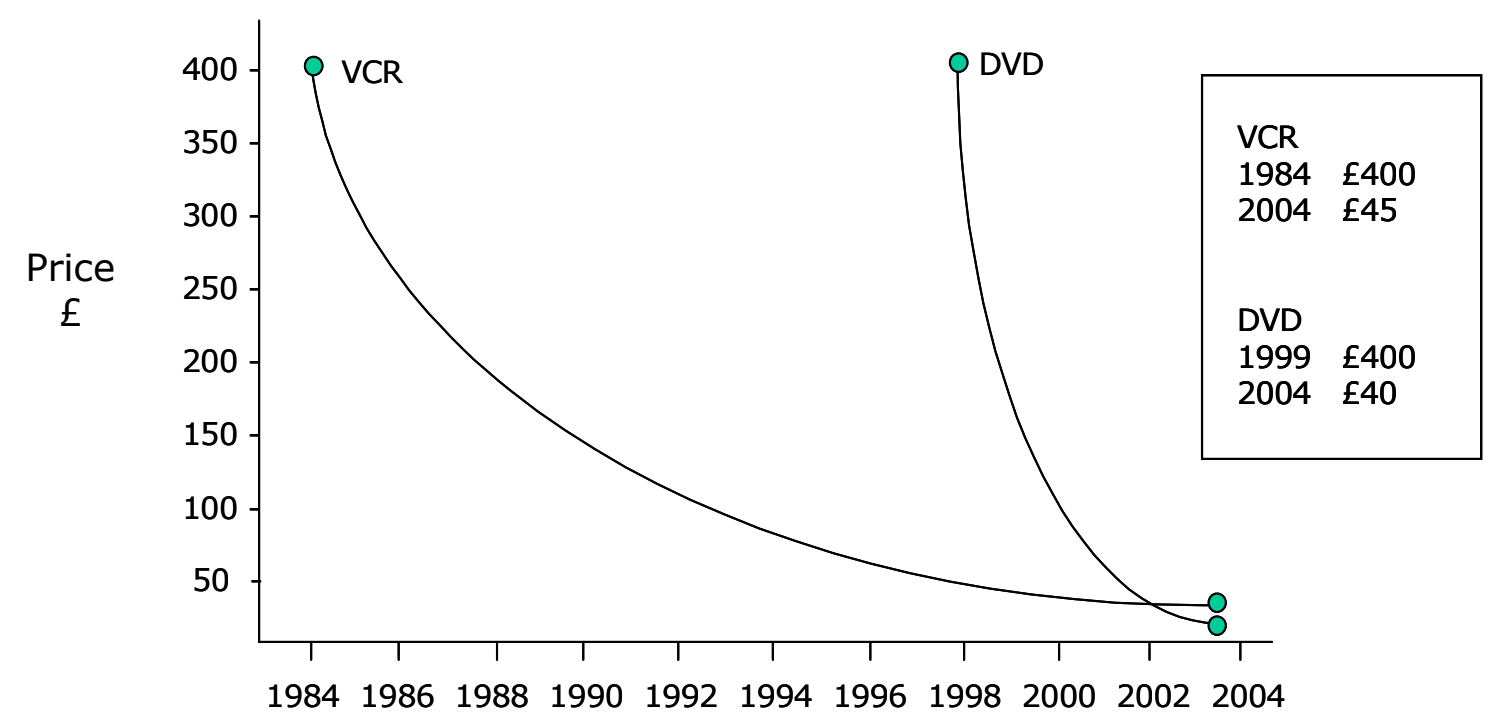

\section{Figure 1. Price deflation in consumer electronics (UK High Street prices)}

A fundamental change in the global competitive landscape is driving prices to levels which in real terms are as low as they have ever been. A number of causal factors have contributed to this new market environment.

First there are new global competitors who have entered the marketplace supported by low cost manufacturing bases. The dramatic rise of China as a major producer of quality consumer products is evidence of this. Secondly, the removal of barriers to trade and the de-regulation of many markets has accelerated this trend enabling new players to rapidly gain ground. One result of this has been over-capacity in many industries (2). Over-capacity implies an excess of supply against demand and hence leads to further downward pressure on price.

A further cause of price deflation, it has been suggested (3) is the Internet which makes price comparison so much easier. The Internet has also 
enabled auctions and exchanges to be established at industry-wide levels which have also tended to drive down prices.

There is also evidence that customers and consumers are more value conscious than has hitherto been the case (4). Brands and suppliers that could once command a price premium because of their perceived superiority can no longer do so as the market recognises that equally attractive offers are available at significantly lower prices. The success of many retailers' own label products or the inroads made by low-cost airlines provide testament to this sea change.

Against the backdrop of a continued downward pressure on price, it is selfevident that, in order to maintain profitability, companies must find a way to bring down costs to match the fall in price.

The challenge to the business is to find new opportunities for cost-reduction when, in all likelihood, the company has been through many previous cost reduction programmes. Our contention is that the last remaining opportunity of any significance for major cost reduction will lie in the wider supply chain rather than in the firm's own operations.

\section{The Challenge of Supply Chain Costs}

It has long been recognised by some that the key to major cost reduction lies not so much in the internal activities of the firm but in the wider supply chain. Back in 1929 Ralph Borsodi (5) expressed it in the following words:-

" .... In 50 years between 1870 and 1920 the cost of distributing necessities and luxuries has nearly trebled, while production costs have gone down by one-fifth .... What we are saving in production we are losing in distribution." 
The situation that Borsodi describes can still be witnessed in many industries today. For example, companies who thought they could achieve a leaner operation by moving to just-in-time (JIT) practices often only shifted costs elsewhere in the supply chain by forcing suppliers or customers to carry that inventory. The car industry, which to many is the home of lean thinking and just in time practices (6), has certainly exhibited some of those characteristics. A recent analysis of the Western European automobile industry (7) showed that whilst the car assembly operations were indeed lean with minimal inventory, the same was not true upstream and downstream of those operations. Figure 1 shows the profile of inventory through the supply chain from the Tier One suppliers down to the car dealerships.

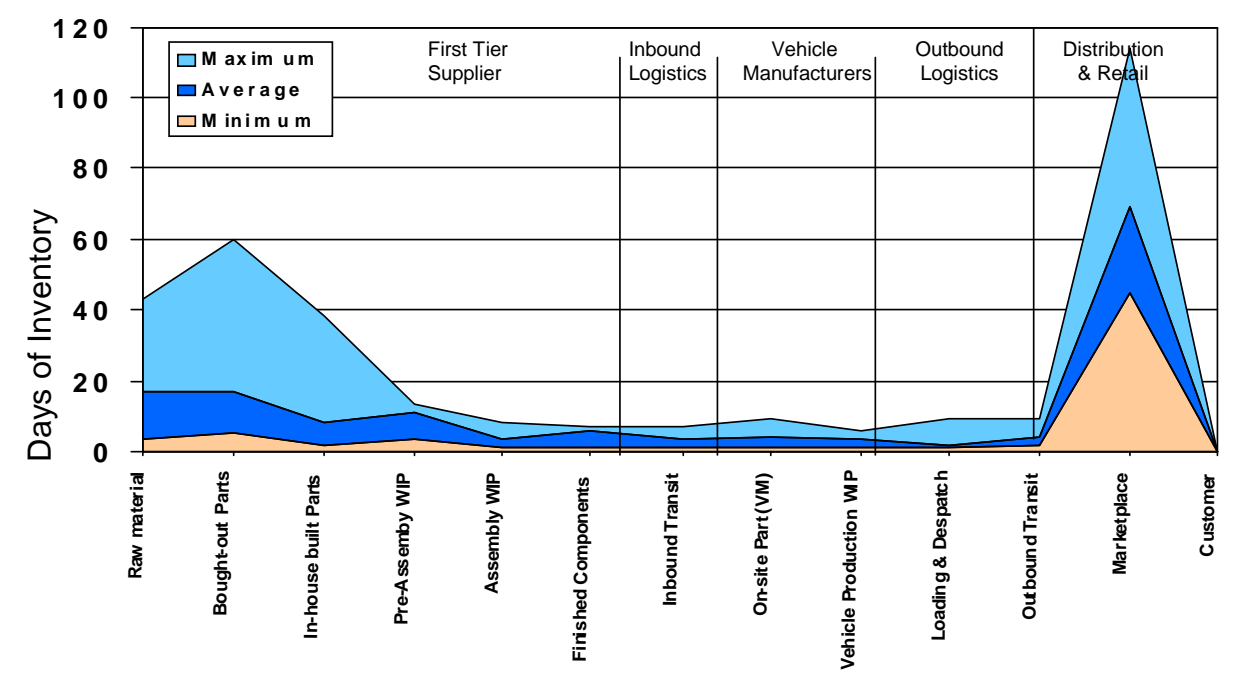

Figure 2. Inventory profile of the automotive supply chain (Source : Holweg (7))

In this particular case the paradox is that most inventory is being held when it is at its most expensive i.e. as a finished product. The true cost of this inventory to the industry is considerable. Whilst inventory costs will vary by industry and by company, it can be argued (8) that the true cost of carrying inventory is rarely less that $25 \%$ p.a. of its value. In the conditions in which 
the automobile industry currently finds itself, this alone is enough to make the difference between profit and loss.

This example illustrates the failure that is frequently encountered to take a wider view of cost. For many companies their definition of cost is limited only to those costs that are contained within the four walls of their business entity. However, it has been argued that today's competition takes place not between companies but between supply chains (9), hence the proper view of costs has to be 'end-to-end' since all costs will ultimately be reflected in the price of the finished product in the final marketplace.

The need to take a supply chain view of cost is further underscored by the major trend that is observable across industries worldwide towards outsourcing. For many companies today, most of their costs lie outside their legal boundaries. Activities that used to be performed in-house are now outsourced to specialist service providers. The amazing growth of contract manufacturing in electronics bears witness to this trend. If the majority of an organisation's costs lie outside the business then it follows that the biggest opportunities for improvement in their cost position will also be found in that wider supply chain.

As out-sourcing increases the supply chain becomes more like a network than a chain (10) and, as a result, the number of interfaces between organisations increases. It is our contention that a growing proportion of total costs in the network occur at these interfaces. These costs have sometimes been labelled 'transaction' costs (11) but in truth they are much more than the everyday costs of doing business. These costs result as much as anything from the lack of transparency and visibility across organisational boundaries. When we talk of visibility and transparency we mean the ability to see clearly from one end of the supply chain to another and, in particular, to share information on supply and demand issues across corporate boundaries. 


\section{Reducing the cash-to-cash cycle time}

From an organisational standpoint a critical performance measure is cash-tocash cycle time. From the moment when a business spends money with suppliers for materials and components, through the manufacturing and assembly process to final distribution and after-market support, time is being consumed. That time is represented by the number of days of inventory in the pipeline, whether as raw materials, work-in-progress, goods in transit, or time taken to process orders, issue replenishment orders, as well as time spent in manufacturing, time in queues or bottlenecks and so on.

Detailed analysis of logistics pipelines often reveals that the length of these cash-to-cash cycles can be significant - often measured in months rather than days. Anything that can be done to refine that end-to-end time clearly means a release of working capital and hence a reduction in cost. The likelihood also is that most of the time in the pipeline will be non-valueadding time and in particular it will be 'idle time' or time spent as inventory that is not on the move.

Supply chain mapping can enable the identification of opportunities for reducing inventory and hence cost. Figure 3 shows an actual map for a particular product, a clothing item. The vertical lines reflect the average inventory over the period of investigation at each step in the chain. 


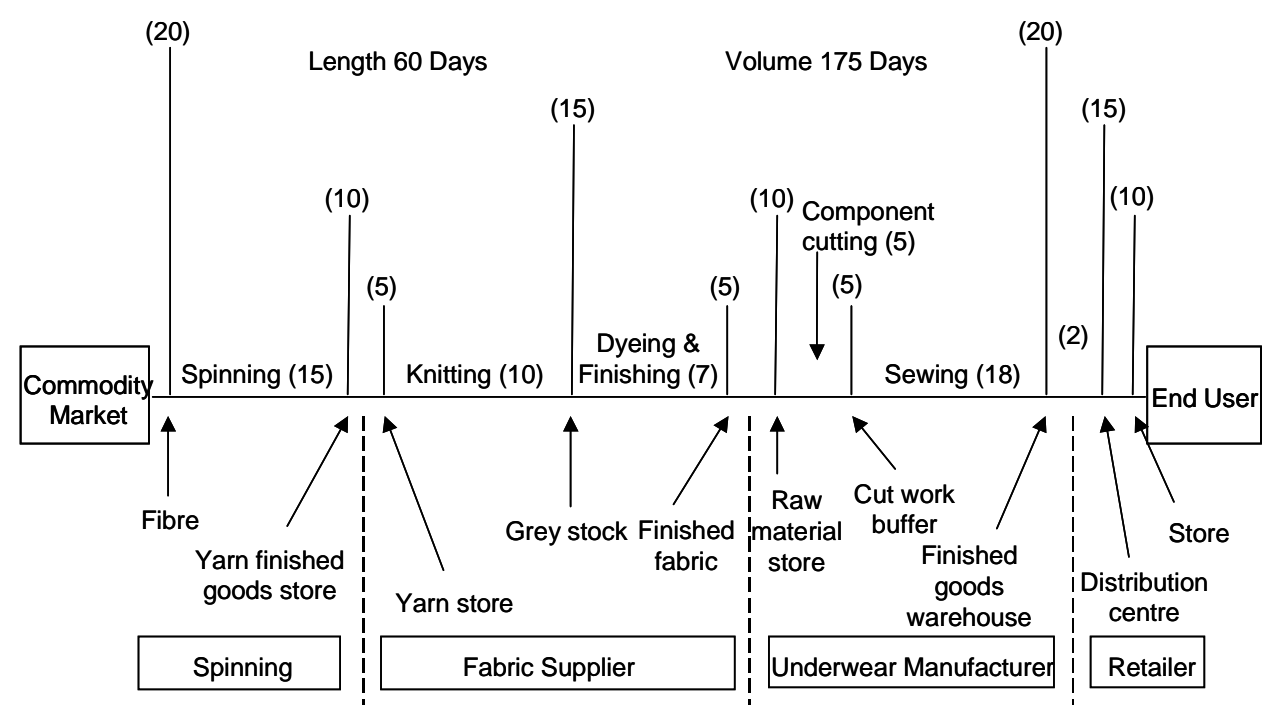

Figure 3. Supply chain mapping - an example (Source : Scott \& Westbrook (12))

Examination of the map highlights the fact that most inventory seems to lie at the interfaces between organisational entities in the chain. In fact there is a duplication of inventory - the supplier carries inventory, their customer carries inventory of the same product. Why is this? The reason is that this inventory is held by both parties as safety stock. Because there is no clear line of sight between the two adjacent entities in the chain - no shared information on the rate of orders or usage - both parties have to buffer against uncertainty with additional inventory. Remove the uncertainty and the need for that inventory is removed also.

Essentially the root cause of this excess inventory is lack of visibility caused by lack of communication. Fortunately there is now a growing recognition of the importance of shared information in the supply chain. In consumer goods distribution, for example, the adoption of 'Collaborative Planning Forecasting and Replenishment' (CPFR) is beginning to make a difference. CPFR, as the phrase suggests, involves the joint determination of forecasts 
through pooled knowledge and information. Based on this agreed view of demand over the forecast horizon the supplier takes responsibility for the replenishment of supplies based upon the actual rate of sale or usage. Significant inventory reductions have been reported in numerous pilot applications along with simultaneous improvement in sales revenue as a result of improved availability (13).

However, despite all these types of initiatives, a fundamentally new approach to pricing is required in order to extract further value; this comes in the form of the supply chain alignment concept discussed below.

\section{Aligning supply chains with customers to create more value}

As competitive pressures have rapidly increased over the last decade, we have been forced to look beyond conventional wisdom because this only leads to diminishing returns. For example, for a long time we have accepted the convention that as service levels rise, so also does the cost-to-serve, exponentially. However, we now understand that this equation is fuelled by both over- and under-servicing, which leads directly to low cost-effectiveness and lost revenue opportunities. Inappropriate pricing regimes and trading terms are integral to this inefficient use of resources. The more realistic paradigm is that cost-to-serve will actually decrease (up to a point) as service profiles increase. See Figure 4 below. 


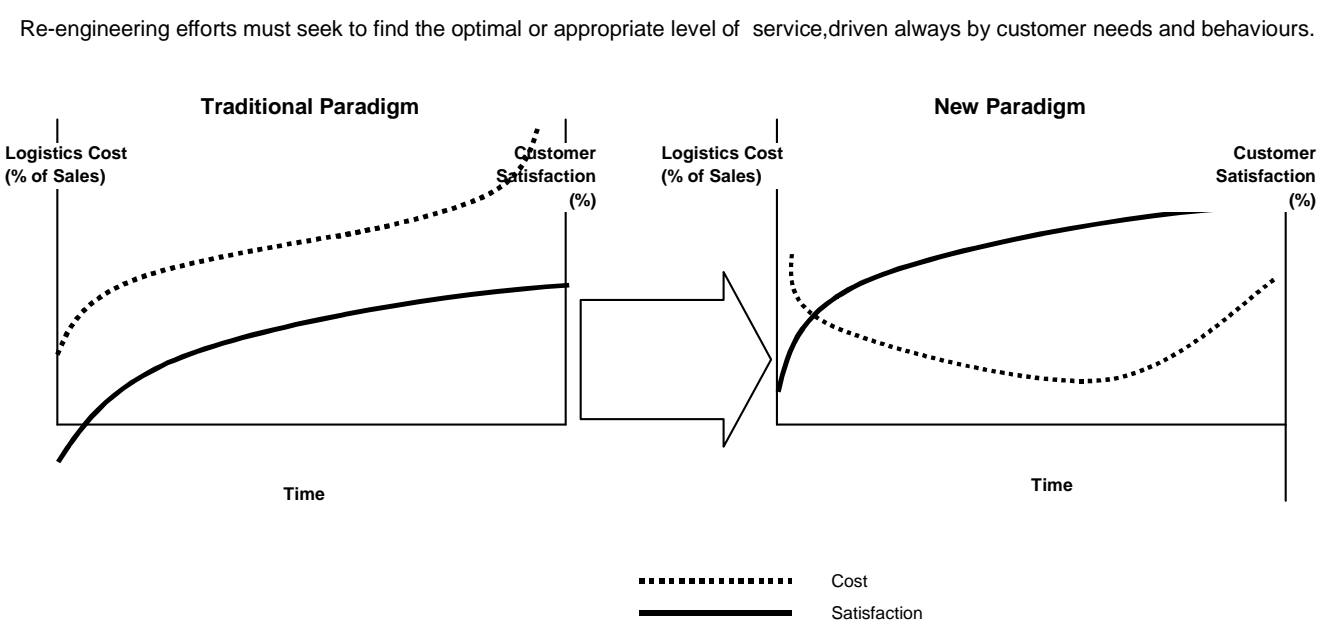

Figure 4 . The cost/service paradigm shift to the 'best of both worlds'
strategy (Source: Gattorna, 2003, p.4 (14))

However, this phenomenon only occurs through improved re-allocation of the firms resources; we call this 'strategic alignment', or simply 'alignment' (15). Driven mostly by the pursuit of functional specialism, the concept of 'alignment' has been largely overlooked, but in today's operating environment, that is where the value lies.

In short, if enterprises wish to produce sustained operational and financial performance, they must align their strategies, cultural capabilities, and leadership styles with customers. Unfortunately, very few organizations in the world today have mastered the art of linking these four levels. The key lies in interpreting the marketplace, and doing so by going beyond economic concepts into the world of human behaviour as depicted in Figure 5 below. 
The Strategic Alignment model brings together the four elements that must be aligned to achieve sustained superior performance

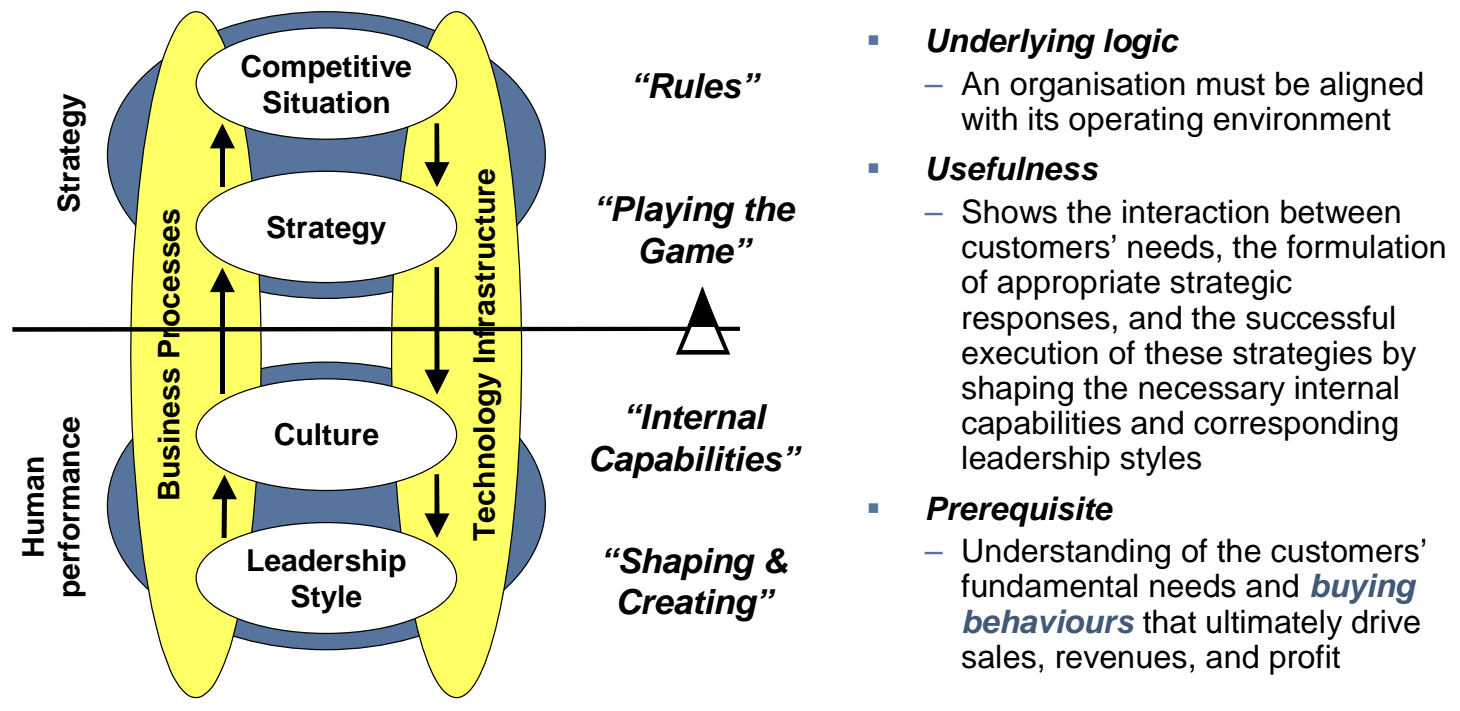

\section{Figure 5. Strategic alignment (Source: Adapted from Gattorna (14) and Gattorna (15))}

For the purposes of this paper we will concentrate on levels 1 and 2 of the alignment model.

From our empirical work it has become obvious that the best way to segment markets is along 'buyer behaviour' lines. Unfortunately, most enterprises use internal parameters that give little indication of how customers wish to buy products and services. This type of segmentation is however belatedly coming to the fore (16).

Essentially, we have found that customers tend to demonstrate a limited number of 'dominant' buying behaviours for any given product or service, and that these behaviours may change if the situation changes. Figure 6 depicts four types of buying behaviour which appear to be present in many product/service situations, but they are not the only ones possible. We have given them labels for ease of discussion. 

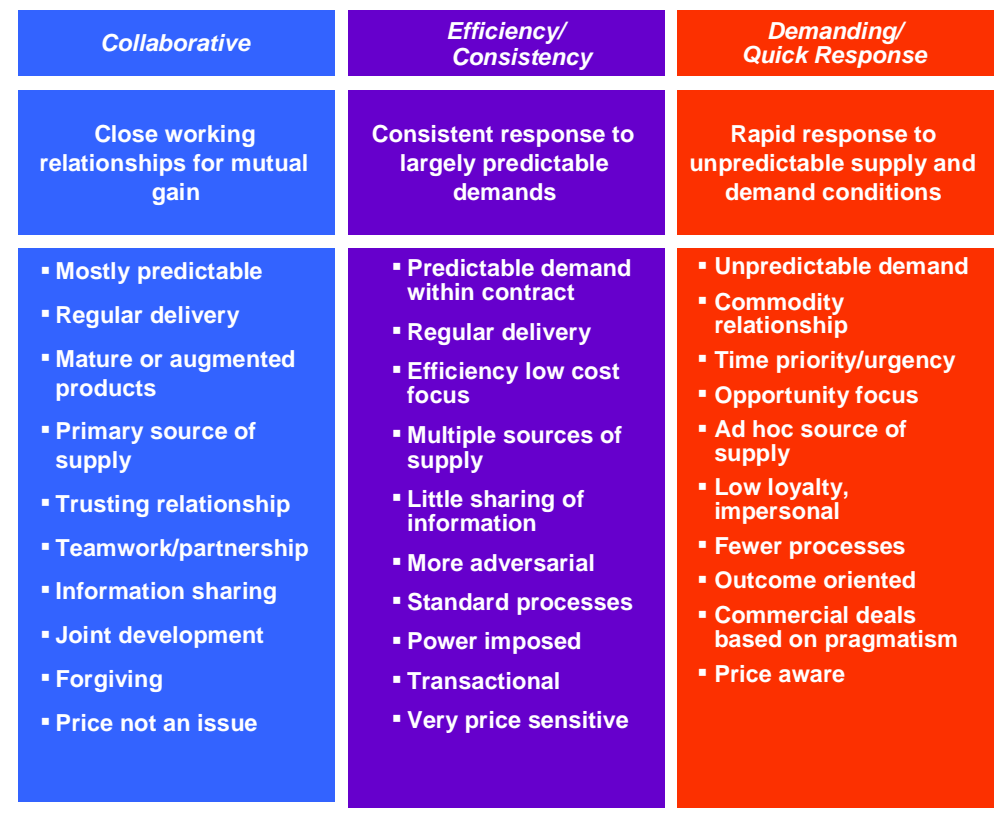

Innovative Solutions

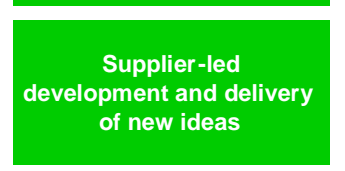

- Very unpredictable

demand

- Higher risk

- Flexible delivery

response

- Innovation focus

- Rapid change

- Individual decision

- making

- Solutions oriented

- Management of IP

- Incentives/ego

- No price sensitivity

Figure 6. Across a broad range of product/service categories, there are a finite number of dominant customer buying behaviours (Source: Adapted from Table 1.3.1, Gattorna, (14), p.32)

The mix of these four buying behaviours will vary across product/service categories and countries.

Clearly, the 'Collaborative' buying behaviour is more driven by a need for trusting relationships and predictability, rather than price. The 'Consistent' buying behaviour is focused on predictable low-cost service, and is very price sensitive. The 'Dynamic' buying behaviour' is price aware, but customers exhibiting this type of response will pay a premium if their largely unpredictable and demanding behaviour is met, at speed. And finally, the 'Innovative Solutions' buying behaviour is only interested in a quick and creative solution, at practically any price!

So the key task becomes one of understanding the mix of these and any similar behaviour segments for a given product/service category. Once this is completed, a pricing strategy by customer-segment type is easily developed, 
especially in business-to-business marketplaces. If the initial segmentation is well done, then even if a particular customer is forced to change their preferred or dominant buying behaviour for short intervals because of internal or external pressures, they would normally move to another of the known buying behaviour options, thereby making the task of responding much easier than the case where exceptions are continually created, often at excessive cost.

So the appropriate 'value propositions', including pricing and other service parameters in this 'multiple supply chain alignment' scenario would look as depicted in Figure 7 below.

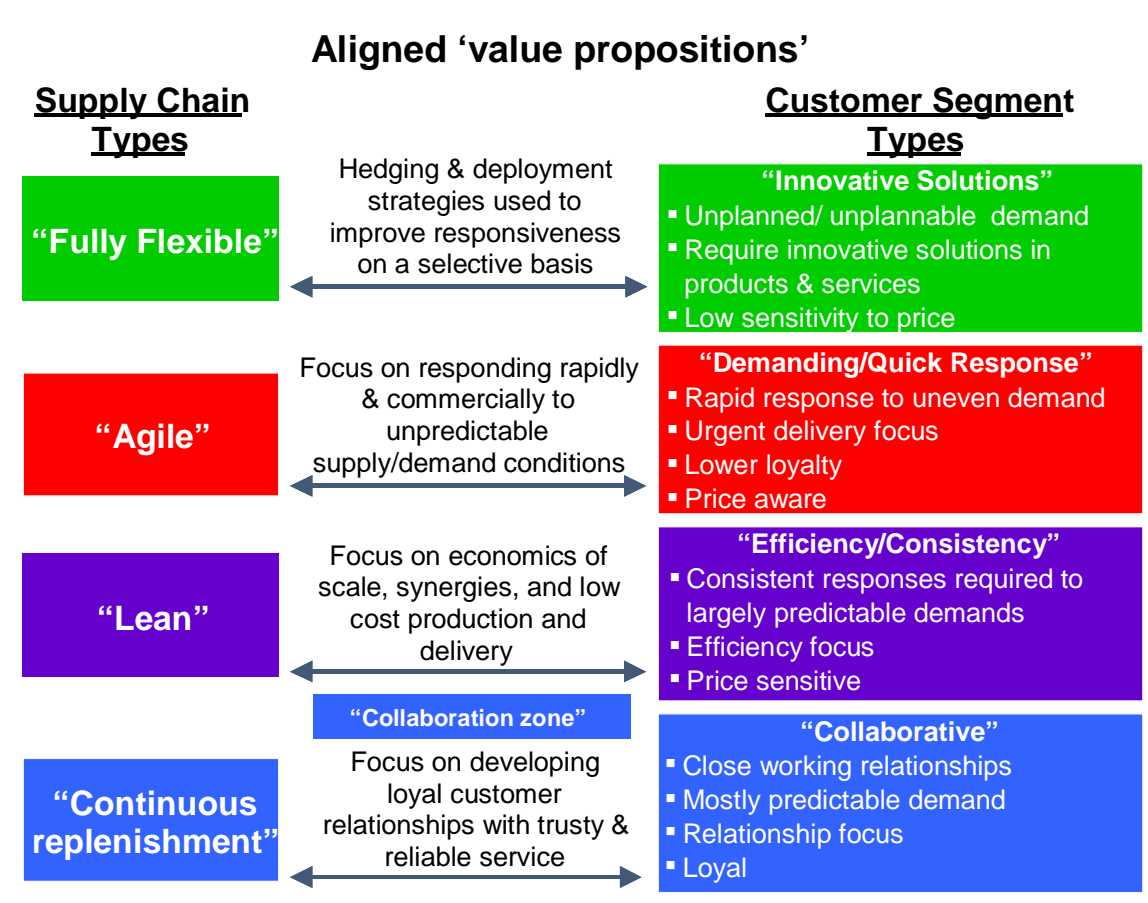

\section{Figure 7. Different 'value propositions' and strategies require different supply chain solutions}

Effectively, we are recommending a 'horses for courses' principle for supply chain design that draws on an understanding of human behavioural as well as economic factors. Adherence to the suggested 'alignment' approach makes the marketplace less of a mystery, and removes much of the trial and 
error style of management that was the hallmark in previous eras when resources were seemingly abundant.

\section{Conclusions}

Because the supply chain offers the best remaining opportunity for cost reduction and value improvement, the management of interfaces in the network is critical. We have argued that the idea of 'alignment', by which organisations adapt their supply chain strategies and processes to customer markets segmented by buyer behaviour, provides a basis for a service-based pricing strategy.

Alignment of supply chain strategies and processes between business partners enables service improvements to be achieved at less cost. By releasing value in this way prices can actually be reduced if necessary whilst still maintaining the supplier's margin. Clearly there are many barriers to successful alignment, not the least being the lack of transparency and visibility across supply chains. The opportunity to 'substitute information for inventory' should be grasped by supply chain partners whenever it arises.

\section{References}

(1) Boston Consulting Group, Perspectives on Experience, 1972

(2) Greider, W., One World, Ready or Not, Simon \& Schuster, 1998

(3) Marn, M.V., Roegner, E.V. \& Zawada, C.C., The Power of Pricing", McKinsey Quarterly, 2003, No. 1, pp 27-39

(4) Frank, R.J., George, J.P. \& Narasimhan, L., "When your competitor delivers more for less", McKinsey Quarterly, 2004, No. 1, pp 49-59 
(5) Borsodi, R., The Distribution Age, New York, D Appleton \& Co, 1929, p.3

(6) Womack, J. \& Jones, D., The Machine that Changed the World, Toronto, Collier Macmillan, 1990

(7) Holweg, M. The Three-Day Car Challenge - Investigating the Inhibitors of Responsive Order Fulfilment in New Vehicle Supply Systems, Ph.D. Thesis, Cardiff Business School, University of Wales, 2002

(8) Lambert, D. \& Stock, J., Strategic Logistics Management, $3^{\text {rd }}$ Edition, Irwin, 1993

(9) Christopher, M.G., Logistics and Supply Chain Management, (1st Edition), Pearson, 1992

(10) Normann, R. \& Ramirez, R., Designing Interactive Strategy, Wiley, 1994

(11) Williamson, O.E., The Economic Institutions of Capitalism, Free Press, 1985

(12) Scott, C. and Westbrook, R., "New Strategic Tools for Supply Chain Management", International Journal of Physical Distribution \& Logistics Management, Vol. 21, No. 1., 1991

(13) Ireland, R. \& Bruce R., "CPFR Only the Beginning of Collaboration", Supply Chain Management Review, September/October 2000, pp 8088

(14) Gattorna, John L (ed), Handbook of Supply Chain Management, Gower Publishing: Aldershot, 2003, p.4. 
Industrial Marketing Management, Vol. 34, No. 2, pp. 115-121, 2005

(15) Gattorna, J.L., (ed), Strategic Supply Chain Alignment, Gower Publishing: Aldershot, 1998, pps. 1-7.

(16) Nunes, Paul, F. and Cespedes, Frank, V., " The Customer has Escaped", Harvard Business Review, November 2003, pps. 96-105. 